\title{
L'on y joue, l'on y danse Quatro datas e um novo director sur le Pont d'Avignon
}

Alexandra Moreira da Silva

Cartaz da $68^{a}$ edição do

Festival de Avignon 2014 .

de Alexandre Singh,

(imagem extraida da

série"Assembly

Instructions, The Pledge de Simon Fujiwara,

uma criação gráfica

do Studio Allez).

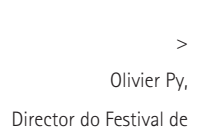

Director do Festival de

Avignon

fot. Carole Bellaïche /

Festival d'Avignon.

da Silva,

dramaturgista e

tradutora, é

actualmente Professora

no Instituto de Estudos

de Teatro da

Universidade Sorbonne

Nouvelle - Paris 111,

investigadora do

Groupe de Recherche

sur la Poétique du

drame moderne et

contemporain (Paris 111)

e colaboradora do

Instituto de Literatura

Comparada Margarida

Losa (FLUP).

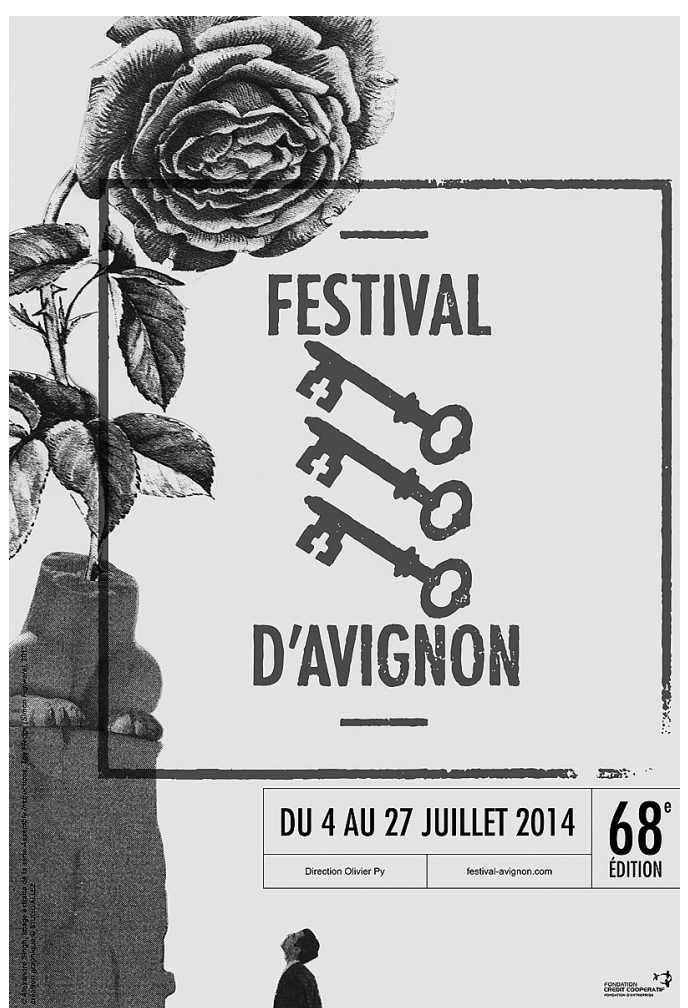

Em Julho de 2013 teve lugar a 67ª edição do mítico Festiva d'Avignon que reúne todos os anos a comunidade teatral internacional em torno de espectáculos, performances, leituras, projecções, encontros, debates e last but not least algumas polémicas mais ou menos acesas. Recordemos, a título de exemplo, a greve dos intermitentes do espectáculo que conduziu à anulação do Festival em 2003, ou a não menos importante "crispação anti-moderna", em 2005, que levou à veemente contestação das escolhas estéticas dos então directores do Festival Hortense Archambault e Vincent Baudriller, e instalou um intenso debate em torno dos limites e das fronteiras do teatro. Julho de 2013 foi precisamente o ano de despedida da dupla Archambault / Baudriller que durante dez anos

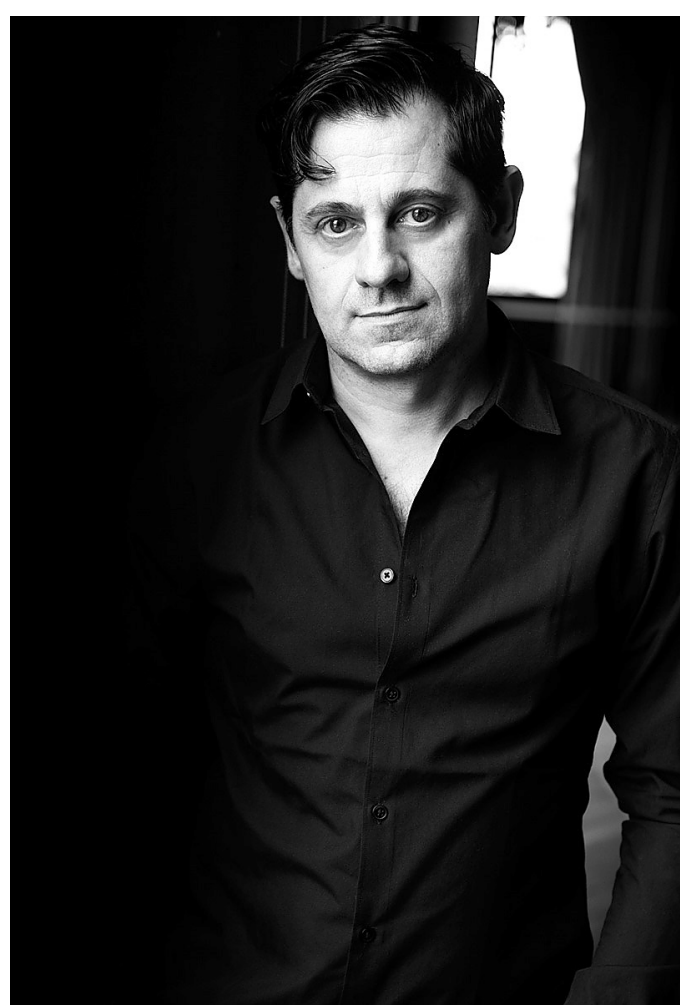

dirigiu e redefiniu o Festival. Cabe agora a Olivier Py, encenador, autor, actor e antigo director do Odéon Teatro da Europa, inaugurar uma nova etapa que, nas suas próprias palavras, se anuncia "intranquila", "irradiante" e "solar" (Py 2014)

2004 - Artistas Associados \& Companhia Conscientes de que, após a desilusão provocada pelo vazio de 2003, o Festival teria de voltar a ser "uma festa" - "a" grande festa do teatro mundial - Hortense Archambault e Vincent Baudriller fazem da palavra "cumplicidade" o mote de um novo conceito de festival que viria a perdurar até à edição de 2013. Ao associarem um artista de renome internacional para juntos "traçarem a carta de um território 
artístico", os dois directores renovam a curiosidade do público e asseguram o interesse da comunidade teatral: "para além das suas próprias criações, afirmam, são as suas interrogações, as suas práticas, os seus entusiasmos que inspirarão livremente o conjunto da programação" (Archambault / Baudriller 2014).

0 encenador alemão Thomas Ostermeier seria 0 primeiro dos treze "artistas associados" que, independentemente da diversidade estética das propostas apresentadas, acabariam sempre por se transformar, de forma quase irremediável, na força centrípeta do evento. As críticas não se fizeram esperar: com as atenções voltadas para as criações destes artistas de renome internacional, frequentemente apresentadas na muito cobiçada Cour d'Honneur, como seriam acolhidos os espectáculos de outros encenadores, coreógrafos e performers igualmente importantes, mas eventualmente menos presentes nos palcos franceses - e nos palcos europeus em geral - muitas vezes por razões puramente geográficas e/ou de produção? A questão, que não deixa de ser pertinente, parece ter perdido importância ao longo dos últimos dez anos, ou pelo menos terá sido deslocada, como veremos mais adiante.

Reconduzida em 2006 e em 2010, a dupla Archambault / Baudrier procurou criar uma série de "pontos de fuga" dentro da própria força centrípeta representada pela figura do artista associado. À minúcia das encenações dos "amantes do texto" como Thomas Ostermeier (2004), Frédéric Fisbach (2007), Valérie Dréville (2008) - única mulher "associada" em 10 anos de Festival - ou Stanilas Nordey (2013), juntaram-se a subtileza coreográfica de Boris Charmatz (2011), o carácter hibrido das sempre surpreendentes propostas de Jan Fabre (2005), Josef Nadj (2005), Romeo Castellucci (2008) ou Christophe Marthaler (2010), ou ainda a reinvenção poética das não menos contagiantes criações/adaptações de Wadji Mouawad (2009), Olivier Cadiot (2010), Simon McBurney (2012) e Dieudonné Niangouna (2013). São encenadores, coreógrafos, autores, actores, performers que se apropriam das artes plásticas, da literatura, da música, da dança, do teatro em todas as suas variantes e (im)prováveis transformações, contribuindo com os seus universos pessoais e heterogéneos para a tão ambicionada redefinição do Festival e do próprio conceito de "teatro".

Espelho da transversalidade reivindicada por grande parte dos criadores contemporâneos, o Festival assumia desta forma, e a partir da Cour d'Honneur, uma cor diferente todos os anos - a cor trazida, sugerida e não raras vezes "impressa" pelo "artista associado". Mas ver Avignon "crescer" ao lado e com a cumplicidade destes artistas pressupunha, também, contar com a sua presença nas diferentes edições do Festival. Assim, Romeo Castellucci, Josef Nadj ou Thomas Ostermeier, para citar apenas alguns nomes, tornaram-se figuras incontornáveis do maior acontecimento teatral europeu, e os seus espectáculos, sempre aguardados com enorme expectativa, baralharam, por vezes, a paleta de cores, tornando-a pontualmente menos singular do que seria desejável. Retrospectivamente, fica ainda a sensação de que a atenção concentrada num núcleo duro de artistas europeus - ou europeizados reduziu a presença e o interesse despertado por espectáculos vindos de outras latitudes.

Se nos pedissem para "associarmos" duas palavras a estes 10 anos de Festival, a nossa sugestão seria talvez, e em primeiro lugar, a palavra "contaminação": do teatro pelas outras artes e pelas diferentes tecnologias, das fronteiras porosas que teimam em separar o real e a ficção, contaminações várias dentro de um "jogo de correspondências"(Ibid.)entre artistas "associados" e artistas "convidados" e, finalmente, contaminação do público geral pela especificidade das propostas trazidas por estes criadores. A segunda palavra seria "coerência": pela aposta firme no conceito de "cumplicidade", e pela sua extensão como princípio basilar das linhas de força que serviram de orientação ao Festival. Na verdade, foi graças àquilo a que poderíamos talvez chamar uma "dinâmica de choque", introduzida por um programa alicerçado em diferentes vasos comunicantes, subtilmente deslocalizados mas coerentes, que o Festival cresceu e completou 10 anos de irreverência, de prazer e de inteligência.

Contra o mistral e outras tempestades, Avignon foi e continua a ser o palco incontornável de um teatro múltiplo, de um "teatro de ideias" (Ibid.). 


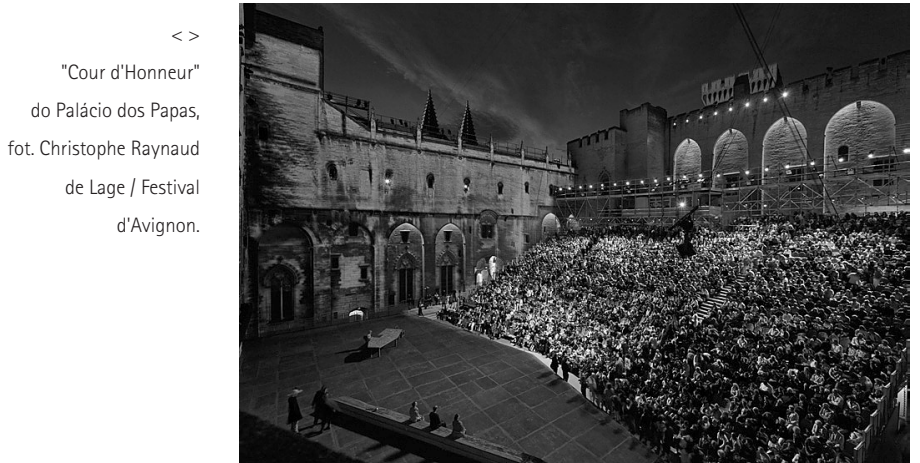

LA FABRICA

interior da sala de ensaio

com bancadas, fot. Illka Kramer. Fabre que, na 59a edição do Festival, ocupou o espaço de "artista associado" deixado por Thomas Ostermeier. L'histoire des larmes e Je suis sang, desde logo apresentados como espectáculos de "dança, teatro e música", foram assumidos como símbolo da rejeição de um "teatro de texto", da desconfiança em relação à palavra e da negação de todo e qualquer conceito de história.

Alguns dias antes do início do Festival, o jornal Libération - quase em jeito de aviso - publicava um artigo biográfico sobre o artista flamengo, apresentando-o como um "carrasco do corpo" que "interroga os humores fisiológicos e utiliza tudo o que escorre, esperma, saliva, sangue, urina, lágrimas, suor"(Masi 2005) nos seus espectáculos. A polémica rapidamente se instalou em torno do artista flamengo e teve como consequência um conjunto de reacções violentissimas por parte de espectadores, críticos e intelectuais (v. Debray 2005), que não hesitaram em contestar as escolhas estéticas dos programadores. Odile Quirot, conceituada crítica do Nouvel Observateur, interrogando-se sobre um possivel (e perverso?) "efeito 'artista associado'" refere-se a Jan Fabre nos seguintes termos: "O problema é que ele monopoliza a Cour d'Honneur, e está de tal forma omnipresente, que o Festiva de 2005 mais parece uma retrospectiva da sua obra..." (Quirot 2005).

Porém - Avignon oblige - várias vozes se levantaram em defesa do artista flamengo. Muitas viriam a integrar, pouco tempo depois, o livro Le cas Avignon 2005, regards critiques, coordenado pelos críticos e ensaístas Georges Banu e Bruno Tackels (Banu / Tackels 2005). Na introdução ao volume, que tem a particularidade de contar com cerca de vinte reacções de jornalistas (Jean- Marc Adolphe, JeanPierre Han, Jean-Louis Perrier...), artistas (Olivier Py, JeanPierre Vincent, Romeo Castellucci, Kryzsztof Warlikowski...) sociólogos (Emmanuel Ethis, Jean-Louis Fabiani, Damien Malinas...), entre outros, pode ler-se: "Este livro nasceu de uma urgência" (/bid.). Mas, de que "urgência" se tratou afinal?

Georges Banu não hesita em comparar esta edição do famoso Festival à não menos célebre Batalha de Hernâni. Referindo-se à crispação anti-moderna que se opôs à importante necessidade de renovação das artes cénicas contemporâneas, Banu recorda que Avignon não é apenas um Festival, é também um espaço e um tempo de reflexão e de criação, onde artistas, agentes culturais e público em geral vivem juntos a tão necessária "experiência da
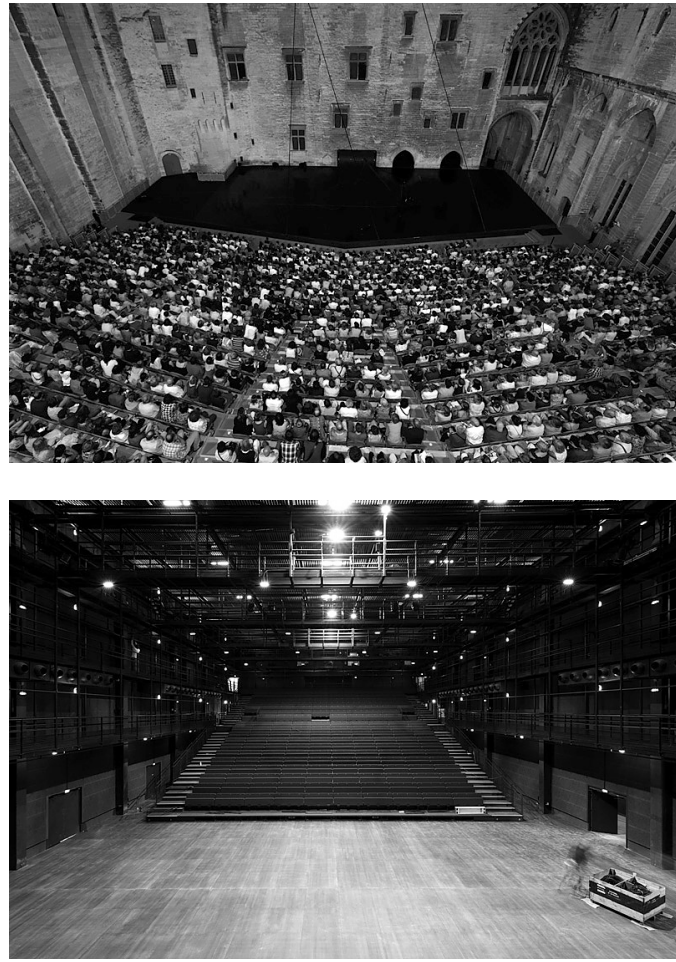

perplexidade" (Banu 2005). Que o Festival d'Avignon se assuma como espaço privilegiado de abertura a estas sucessivas transformações é simplesmente uma necessidade - para não dizer uma obrigação. "Nisso consiste precisamente a dignidade do Festival, afirma Georges Banu, não se limitar ao déjà-vu, ao catalogado, mas ousar [...] colocar o público num estado de insegurança artística," (Ibid.).

A polémica instalada em torno do "artista associado" parece ter criado algumas "distracções", relegando para segundo plano a importância de alguns momentos altos desta edição do Festival, como, por exemplo, as performances da incontornável Marina Abramovic, ou os espectáculos de Olivier Py, Jean-François Sivadier, JeanFrançois Peyret, Jacques Delcuvellerie, Hubert Colas, Thomas Ostermeier, Romeo Castellucci, Krzysztof Warlikowski, entre outros, com propostas a partir de textos clássicos de autores do repertório vilariano (A vida de Galileu de Bertolt Brecht, A Morte de Danton de Georges Buchner, Hamlet de Shakespeare...) e de textos contemporâneos (Ruinas de Sarah Kane, Os vencedores de Olivier Py, Kroum de Hanokh Levin...).

Urgente será, portanto, não andarmos distraídos, E, já agora, termos coragem para acompanhar aqueles que não raras vezes se apresentam como "cavaleiros do desespero" ${ }^{1}$ Até porque são precisamente esses que, no final da aventura, nos permitem dizer "eu estive lá".

No ano seguinte, caberia a Josef Nadj - artista menos controverso igualmente presente na controversa edição de 2005 com o belíssimo Last Landscape - assumir o pape de "artista associado" e festejar o sexagésimo aniversário do Festival d'Avignon.

2013 - A FabricA, um (novo) espaço de criação Era já o sonho de Jean Vilar e esteve sempre nos projectos dos sucessivos directores do Festival, mas só em 2013, com Hortense Archambault e Vincent Baudriller viria a tornar-se realidade: a FabricA (cujo A maiúsculo presente 


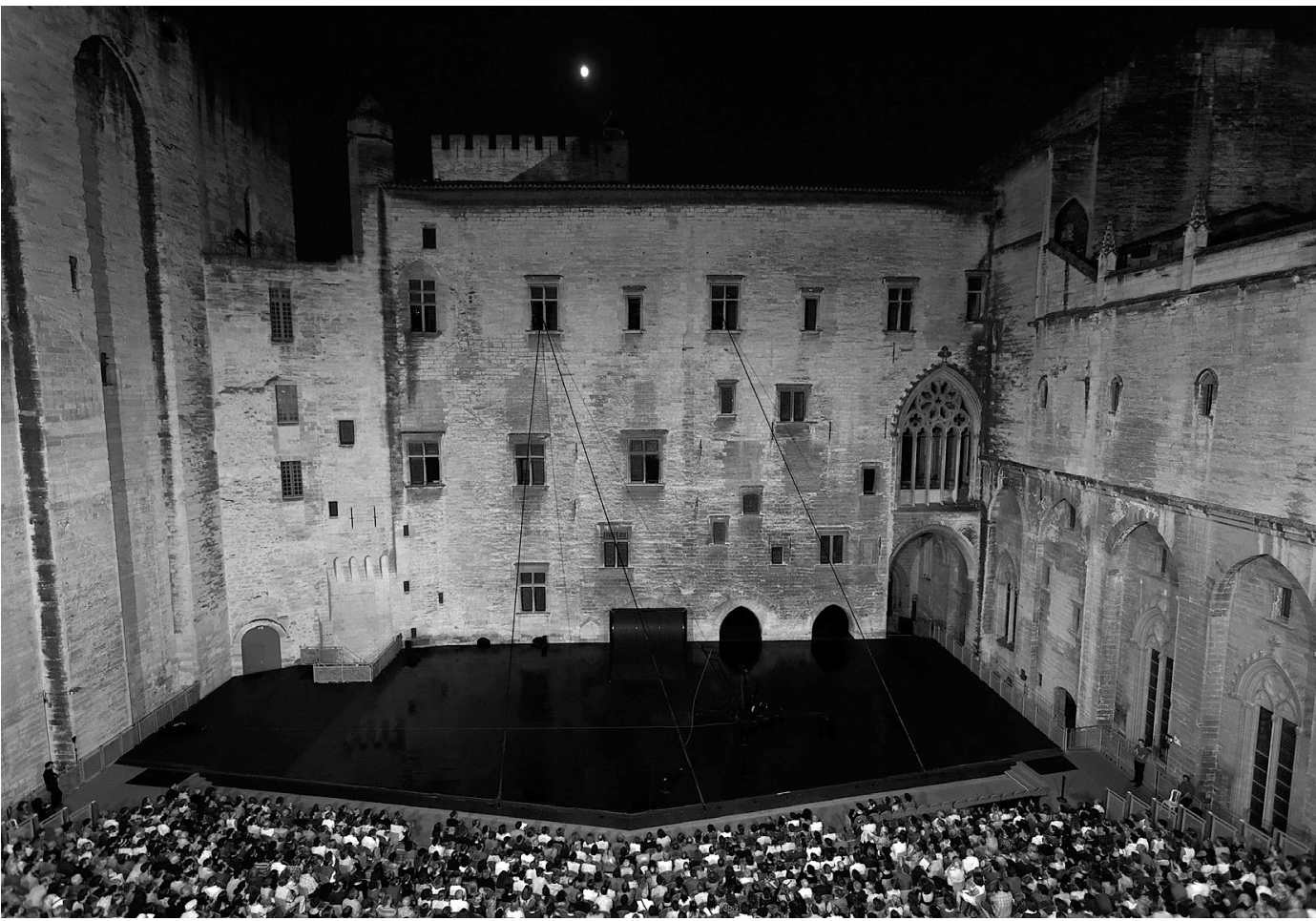

no final da palavra e na fachada principal do edifício remete, obviamente, para o logótipo do Festival) é o novo espaço polivalente da cidade que acolhe um dos maiores festivais de teatro do mundo mas que, paradoxalmente, e apesar de ter conseguido multiplicar os espaços de apresentação de espectáculos, não reunia ainda as condições técnicas necessárias para acolher o número cada vez mais importante de criadores e as suas exigentes propostas.

Com um custo de dez milhões de euros, este projecto depurado e funcional da arquitecta de origem polaca Maria Godlewska, construído num bairro em processo de reabilitação a uns escassos 1000m das muralhas, é, antes de mais, um espaço de trabalho, um espaço de criação, com uma sala de ensaios - transformável em sala de espectáculo com 600 lugares durante o mês do Festival - e um claustro à volta do qual se distribuem 18 estúdios, um espaço técnico, um refeitório e uma cozinha que permitem acolher os artistas em residência.

Inaugurada a 5 de Julho pelo Grupo $F^{2}$, a FabricA viria a receber logo a seguir dois dos nomes mais importantes do teatro europeu, e duas das maiores e mais exigentes produções da 67a edição do Festival: Nicolas Stemann que com o Thalia Theater de Hamburgo e uma equipa constituida por 60 pessoas apresentou Fausto / e // de Goethe, e o polaco Krzysztof Warlikowski (Nowy Teatr) que instalou neste novo espaço o seu Kabaret Warszawski.

No próximo mês de Julho, a FabricA acolhe os espectáculos de dois criadores franceses: Orlando ou l'impatience de Olivier Py (de 5 a 16 de Julho) e um ousado Henry Vlem versão integral (18 horas de espectáculo) do jovem encenador Thomas Jolly (21, 24 e 26 de Julho). Durante 0 ano, as equipas criativas dos dois projectos foram partilhando a casa que os irá acolher em julho, juntamente com Nathalie Garraud e Olivier Saccomano que apresentarão o espectáculo itinerante Othello Variation a partir de Shakespeare.
Referindo-se às expectativas criadas em torno deste novo espaço de criação situado fora das muralhas da cidade, Olivier Py salienta a importância de uma "nova descentralização cultural a inventar": "foi a partir da FabricA que o Festival [...] iniciou, em Setembro de 2013, esta experiência de uma instituição aberta à sensibilização, à partilha da reflexão e do trabalho em curso, ao longo de onze meses". E acrescenta: "[...] não são os bairros que precisam de nós, mas nós que precisamos dos bairros, não é o real que precisa da poesia, é a poesia que precisa do real."(Py 2014)

\section{4 - Do esPYrito da indisciplina}

A escolha não será consensual, mas as expectativas são muitas: é a primeira vez, desde a morte de Jean Vilar, que criou e dirigiu o Festival d'Avignon entre 1947 e 1971 (v. Tackels 2007), que um artista é nomeado director desta grande festa do teatro internacional. Olivier Py, poeta e verdadeiro "animal de palco", respira teatro. Os seus textos e encenações não passaram despercebidas no panorama do teatro francês e internacional, bem pelo contrário. Espectáculos como La servante, une histoire sans fin, com uma duração de 24 horas (Avignon, 1995), Le visage d'Orphée (Avignon, 1997), Les vainqueurs (Avignon, 2005) o inesquecivel Miss Knife, personagem de cabaret que Py cria e interpreta pela primeira vez em 1996, no mesmo Festival, ou a (premonitória?) homenagem a Jean Vilar L'énigme Vilar (2006), espectáculo que encerra, na Cour d'Honneur, a 60ª edição do Festival, fazem de Olivier Py um nome incontornável da cena contemporânea e um habitué de Avignon.

Tendo, ainda, dirigido, entre 1997 e 2012, duas das mais prestigiadas instituições teatrais francesas: o Centro Dramático de Orléans (1997) e o Odéon - Teatro da Europa (2007), o criador Olivier Py chega agora, tranquilamente, como director à "cidade dos Papas", para re-inventar um Festival "intranquilo". Consciente de que "[...] Avignon está
Companhia de teatro de rua que, durante quarenta minutos, e perante cerca de 8000 espectadores, multiplicou as cores e as formas do edificio com o virtuosissimo espectáculo pirotécnico Ouvert! 
LA FABRICA, exterior, entrada para o público à noite fot. Illka Kramer.

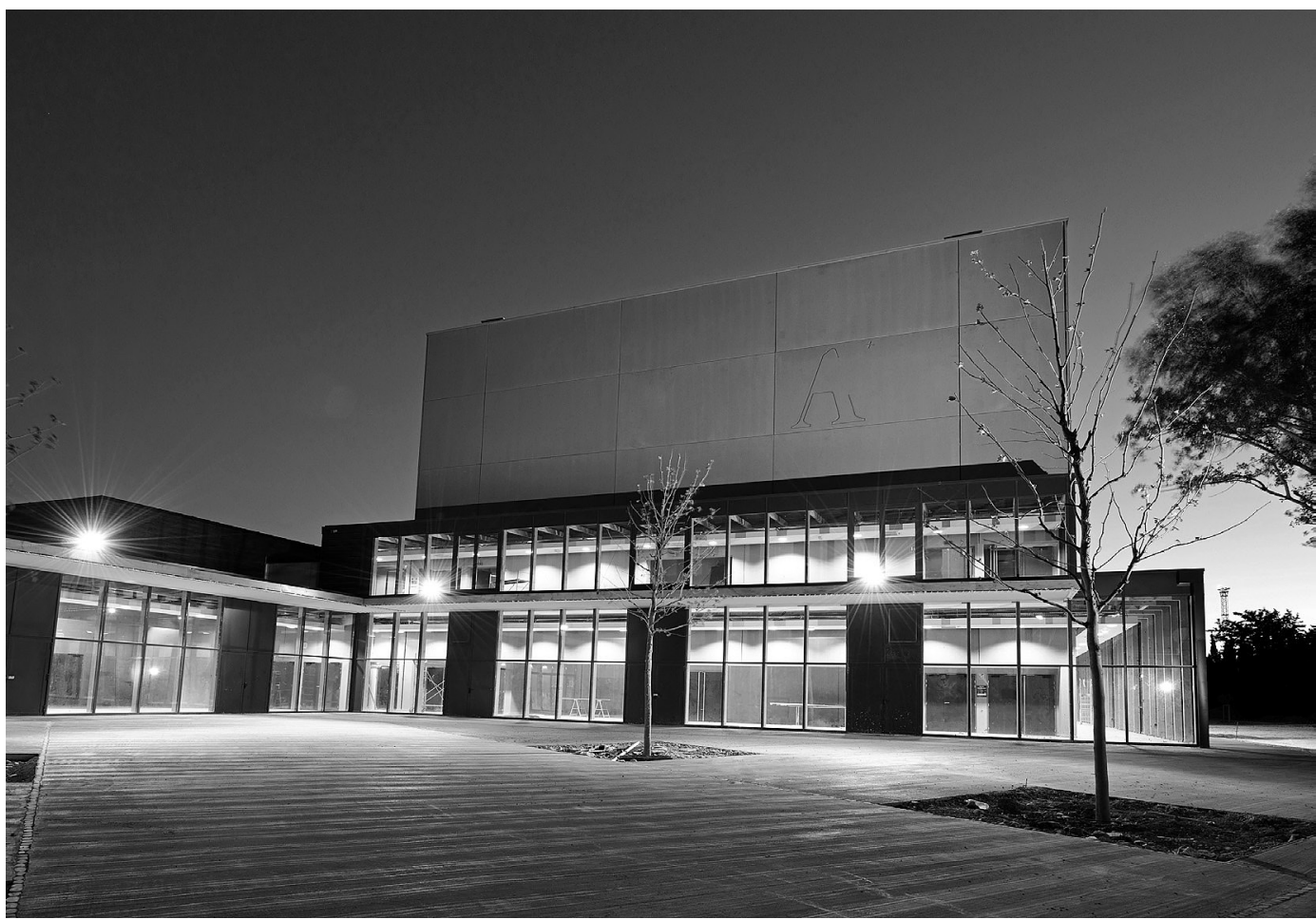

na origem do movimento da descentralização e do teatro público" (Py 2014), o que transforma este evento num marco importante - "iniciador", nas palavras de Py - da politica cultural francesa, o novo director assume o desafio de (re)criar um "Festival político e poético", promovendo, como era já seu desejo enquanto director do Odéon, uma "comunidade de espírito o mais ampla possível"(Py 2007: 18), "indisciplinar" (Py 2014), disposta a ultrapassar as barreiras e os limites sociais e estéticos.

A edição de $2014^{3}$ propõe um Festival que, mais do que "nacional na região", quer ser "internacional no bairro" 17 países, 5 continentes representados, uma clara aposta no eixo "vertical e fundador" norte-sul (com destaque para os criadores gregos e dos mundos árabes), 28 criações (das quais 7 são recriações); 25 artistas pisam, pela primeira vez, os palcos de Avignon, e cerca de metade tem menos de 35 anos; o público vai também poder ver/ouvir os textos de 14 autores vivos, assistir a 3 espectáculos para a infância e juventude, e pisar o chão de 5 novos espaços. Destaque ainda para as novas propostas de assinatura "abonnement jeune" e "abonnement grand spectateur" e para a redução de algumas tarifas, medidas que visam acompanhar "a fidelidade e a descoberta", permitindo ao público mais jovem e aos "resistentes" uma significativa redução no custo da aventura.

0 Festival abre no dia 4 de Julho com um espectáculo "europeu", e um texto do repertório vilariano: Le prince de Hombourg do alemão Heinrich von Kleist (tradução de Eloi Recoing e Ruth Orthmann), encenado pelo italiano Giorgio Barberio Corsetti, com a participação de actores belgas e franceses. No dia 27 de Julho, o encerramento desta que promete ser uma festa "solar" mas sempre "intranquila" estará a cargo da carismática e muito politizada banda francesa Têtes Raides, que brindará o público com o concerto "Corps et mots", na Cour d'Honneur. em http://www.festival-

avignon.com/en quarenta espectáculos de teatro, dança, música e literatura mas também a debates "indisciplinares", leituras e cinema. Nos estreantes, destacamos a presença da companhia brasileira Teatro da Vertigem, dirigida por António Araújo, que apresentará o espectáculo Dire ce qu'on ne pense pas dans des langues qu'on ne parle pas, a partir de um texto original de Bernardo Carvalho. Nos habitués, não podemos deixar de salientar a presença de Claude Régy, que leva a Avignon uma produção franco-japonesa de um dos seus textos-fetiche: Intérieur de Maurice Maeterlinck. Mas muito mais haverá para ver e ouvir. De Auckland a Tel Aviv, de Atenas ao Cairo, ou de Sibiu a Santiago do Chile, a $68^{a}$ edição do Festival d'Avignon parece querer afirmarse como palco privilegiado de um verdadeiro Teatro das Nações, onde não faltam ecos do lendário Festival de Nancy.

Indisciplinar, intranquila, irradiante e solar - que a festa comece! Porque "tal como o amor precisa de quarto, o mundo precisa de teatro." (Py 2014)

\section{Referências bibliográficas}

ARCHAMBAULT, Hortense / BAUDRILLER, Vincent (2004), Editorial do

Programa da 58 edição do Festival d'Avignon, Julho.

BANU, Georges (2005), "On est dans un temos de réaction face au moderne",

in Libération, 26 e 27 de Novembro.

BANU, Georges / TACKELS, Bruno (2005) (org.), Le cas Avignon 2005, regards critiques, Montpellier, Éditions l'Entretemps.

DEBRAY, Régis (2005), Sur le pont d'Avignon, Paris, Flammarion.

MASI, Bruno (2005), "Bourreau du corps", in Libération, 25 e 26 de Junho. PY, Olivier (2014), "Tout ce qui nous dépasse", texto publicado no pré-

programa do Festival d'Avignon 2014.

--(2007) Discours du nouveau directeur de l'Odéon, Arles, Actes-Sud, p. 18.

QUIROT, Odile (2005), "On danse sur le pont d'Avignon", Le Nouvel

Observateur, 7-13 de Julho.

TACKELS, Bruno (2007), Les voix d'Avignon, Paris, France Culture - Seuil. 